\title{
Peak expiratory nitric oxide differences in men and women: relation to the menstrual cycle
}

\author{
Sergei A Kharitonov, Ron B Logan-Sinclair, Carolyn M Busset, Elliot A Shinebourne
}

\begin{abstract}
Objective-To develop a method to measure end expiratory nitric oxide concentration and to use it to determine whether there are sex related differences between healthy men and women.

Design-Modification of commercially available chemiluminescent analyser to allow endogenous nitric oxide (endothelium derived relaxing factor) to be measured in a single slow forced vital capacity manoeuvre with evaluation of between and within subject variability. Serial measurements in women throughout the menstrual cycle.
\end{abstract}

Setting-Specialist referral hospital.

Subjects-59 healthy volunteers (40 men and 19 women).

Results-Mean (SD) peak expiratory concentrations of nitric oxide in men (75 (20) ppb (parts per billion)), and women (70 (37) ppb (first measurement)) were $>5$ times those previously recorded. In women concentrations at midcycle (150(39) ppb) were significantly higher (mean difference 94.9(41), $P<0.001$ ) than during menstruation (59(25) ppb).

Conclusion-Nitric oxide production (endothelium derived relaxing factor activity) is influenced by cyclical hormonal changes in women. There was an increase of more than $100 \%$ at mid cycle. This may be pertinent to the lower risk of cardiovascular disease in premenopausal women.

(Br Heart $\mathcal{F} 1994 ; 72: 243-245)$

Nitric oxide, synthesised from the amino acid L-arginine, is now well established as accounting for the biological activity of endothelium derived relaxing factor. ${ }^{12}$ In the cardiovascular system nitric oxide acts as a physiological regulator of blood flow and pressure, whereas when released after immunological stimulation, nitric oxide can cause pathological vasodilation and tissue damage. Under physiological conditions nitric oxide is released by a constitutive $\mathrm{Ca}^{2+}$ dependent enzyme (nitric oxide synthase), whereas under immunological stimulation nitric oxide is derived from the action of a $\mathrm{Ca}^{2+}$ independent inducible enzyme. ${ }^{3}$ Endogenously produced mixed expired nitric oxide has been previously measured by chemiluminescence in animals and humans. ${ }^{4}$ The slow response time and low sensitivity of some commercially available analysers precludes the direct measurement of nitric oxide during the respiratory cycle. We have modified our nitric oxide analyser to shorten the response time substantially from 90 to eight seconds. This has allowed us to measure expiratory nitric oxide directly during slow exhalation in a cohort of normal volunteers. Recent evidence that oestrogens influence endothelium derived relaxing factor activity prompted us to undertake serial measurements of expired nitric oxide in women during the menstrual cycle. ${ }^{5}$

\section{Subjects and methods}

Fifty nine healthy volunteers were recruited from our staff. There were 40 men (age 36(4) and 19 women (age 33(7)). All were healthy, receiving no medication, and were non-smokers. None of the women in this study were taking oral contraceptives. Each volunteer was asked to inhale room air to total lung capacity and then to exhale slowly (range 30-75 s) into a Teflon tube (4 mm internal diameter) connected directly to the nitric oxide analyser, until they reached residual volume. The choice of Teflon tubing was made after a series of measurements showed that the use of a plastic mouthpiece substantially reduced the nitric oxide concentrations through adsorption by polythene. At least three manoeuvres were performed by each subject with a short rest between each and the best of three reproducible measurements was used in the analysis. Thirty three of the volunteers (26 men, seven women) repeated the study the next day. A series of measurements were made on the women at frequent intervals during their menstrual cycle; the last measurement was made the same number of days after the start of menstruation as the first set of measurements.

The expired nitric oxide was measured by a chemiluminescent nitric oxide analyser (Model 2107, Dasibi Environmental Corporation, Glendale, CA, USA), designed for nitric oxide concentrations within the ranges $2000-4000$ parts billion (ppb) and 40-400 parts million ( $\mathrm{ppm}$ ) in a continuous, ambient air sample. The analyser has a highly stabilised measurement capability (zero drift without auto zero $1 \mathrm{ppb} / 24$ hours for extended periods) and operates over a wide range of ambient temperatures $\left(5-40^{\circ} \mathrm{C}\right)$ and humidity $(0-95 \%)$ without adverse effect on measurement accuracy. Sampling rate is fixed at $200 \mathrm{ml} / \mathrm{min}$. Within a chemiluminescent analyser nitric oxide reacts with ozone gener- 
ated in a reaction chamber. The intensity of light generated in the reaction is proportional to the reactant concentration of nitric oxide. The $95 \%$ response time of the analyser was 90 seconds, which was too long to allow measurement of end expiratory or alveolar nitric oxide concentration even in a long exhalation. Therefore we modified the electronic circuitry and sent the precomputer analogue signal directly to a chart recorder. This resulted in an improved response time of eight seconds. The modification did not significantly alter zero drift. The zero signal (primary photomultiplier tube dark current) variations were also stable during measurements. Linearity remained within $1 \%$ and the noise level was $\leqslant 1 \mathrm{ppb}$. The instrument was calibrated daily with nitric oxide free certified compressed air to set absolute zero and then a certified concentration of nitric oxide in nitrogen of 89 ppb. Ambient air nitric oxide concentration was recorded and the absolute zero was adjusted before each measurement by flushing the nitric oxide analyser with nitric oxide free certified compressed air. Results were displayed on a chart recorder and compared with the signal generated from the calibration gas. In 33 subjects the reproducibility of individual nitric oxide measurements was assessed by the Bland and Altman method, ${ }^{6}$ between visit 1 and 2 (successive days). Differences between peak expired nitric oxide concentrations produced during menses and those produced during the last third of the follicular phase and the beginning of the luteal phase were compared with Student's $t$ test.

\section{Results}

Figure 1 shows the reproducibility of individual nitric oxide measurements between visit 1 and visit 2 (successive days). In 47 subjects we compared the plateau signal corresponding to peak expiratory nitric oxide concentration with the area under the curve, extrapolated to zero on the slow exhalation manoeuvre (fig 2 ). This showed a high correlation $(r=0.98 \quad(P<0.001)$ and we have therefore considered only plateau concentrations in the analysis.

Figure 1 Reproducibility of individual measurements of nitric oxide (NO) concentration on two successive days.

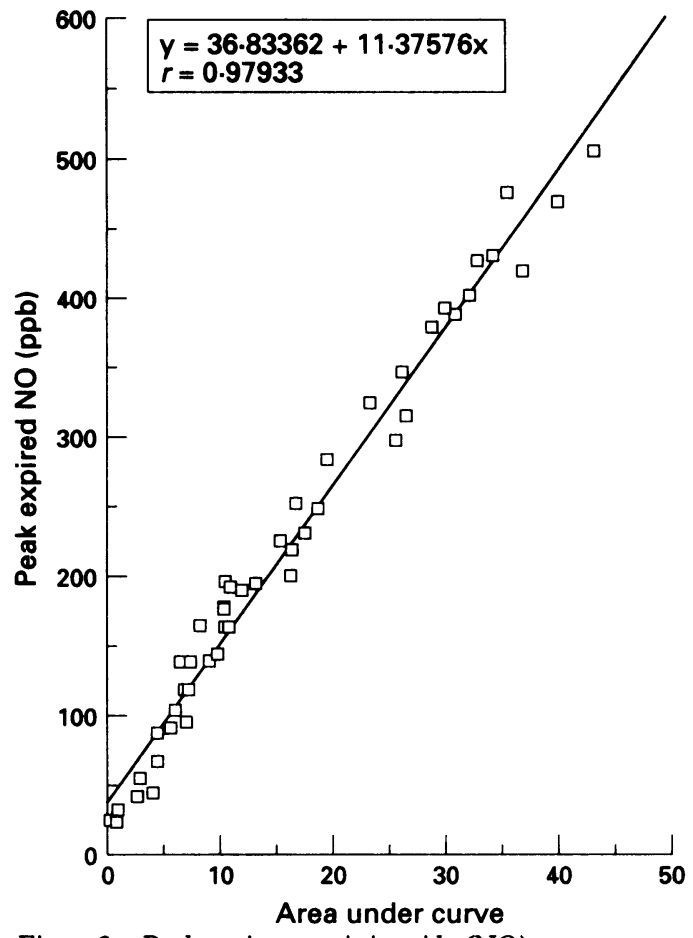

Figure 2 Peak expiratory nitric oxide (NO) concentration $v$ the area under the corresponding respiratory curve.

In the table we show the mean (SD) data for men and women; the data represent the first occasion on which each subject was studied. This shows that women had similar nitric oxide concentrations to men and also that variability was greater in women.

Peak expired nitric oxide concentrations are shown in relation to the menstrual cycle (fig 3). During the last third of the follicular phase and the beginning of the luteal phase of menstruation the mean nitric oxide values (150 (39) $\mathrm{ppb}$ ) are highly significantly greater (mean difference $=94.4(41) ; \mathrm{P}<0.001)$ than those produced during menses $(59(25) \mathrm{ppb})$.

\section{Discussion}

Modification of our chemiluminescent nitric oxide analyser to give an improved response time of eight seconds enabled us to measure nitric oxide concentration throughout slow exhalation and thus allowed us to record peak expired nitric oxide concentration in humans. This study does not give information as to the site of origin of the expired nitric oxide as not only pulmonary endothelial cells but macrophages or other cells in the airways or alveolar surface may be responsible. ${ }^{3}$

The plateau concentrations of nitric oxide we measured are at least five to 20 times

Peak expiratory nitric oxide (NO)

\begin{tabular}{llll}
\hline & $\begin{array}{l}\text { Men } \\
(\text { mean }(S D), \\
n=40)\end{array}$ & $\begin{array}{l}\text { Women } \\
(\text { mean }(S D), \\
n=19)\end{array}$ & P value \\
\hline NO (ppb) & $75(20)$ & $70(37)$ & $>0.05$ \\
Age (yr) & $36(4)$ & $33(7)$ & $>0.05$ \\
\hline
\end{tabular}


Figure 3 Mean (SD) peak expired nitric oxide (NO) concentrations shown in relation to the days of the menstrual cycle.

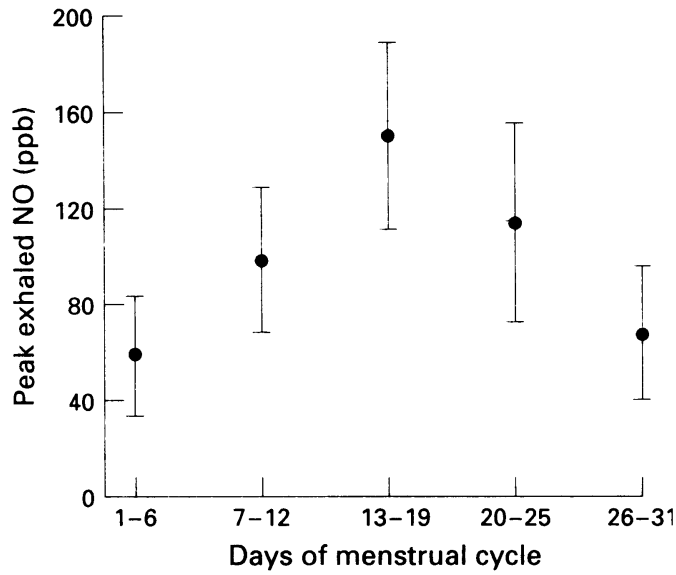

higher than those recorded previously. ${ }^{4}$ We presume this is because we were measuring the peak expiratory nitric oxide during a slow exhalation (30-75 s), rather than the more dilute mixed expired nitric oxide collected during normal breathing as measured by other workers. Our subjects exhaled directly into the analyser through a Teflon tube, which is known not to adsorb nitric oxide. Nitric oxide concentration in samples collected over several minutes may be an underestimate because of the short half life of nitric oxide, (3-30 s), and also because nitric oxide may have been adsorbed on the walls of the collecting system.

We have also shown, for the first time, a striking and highly significant increase in nitric oxide production in women during the middle part of the menstrual cycle. This raises interesting questions. The highest nitric oxide concentrations correspond to the mid cycle increase in oestradiol, oestrone, luteinising and follicle stimulating hormone, but precedes the increase in progesterone concentrations (secretory phase). Oestrogens, particularly oestradiol- $17 \beta$, are known to be vasodilator substances. They increase cardiac output and arterial blood flow velocity, and decrease systemic vascular resistance and systolic and diastolic blood pressure. ${ }^{78}$ Ostradiol $17-\beta$ relaxes rabbit coronary arteries both by an endothelium independent ${ }^{9}$ and by an endothelium dependent mechanism. ${ }^{10}$ Both short-term ${ }^{11}$ and long-term treatment with ethinyl oestradiol modulate responses to acetylcholine in monkey coronary arteries through an effect on endothelium derived relaxing factor (nitric oxide). ${ }^{12}$

Premenopausal women have less cardiovascular disease, such as hypertension or coronary atherosclerosis, than age matched men. After the menopause the incidence of cardiovascular and cerebrovascular mortality increase. Hormone replacement therapy, however, in postmenopausal women reduces mortality for both categories of disease by a half to one third..$^{713}$ Various mechanisms could account for the protective effect of oestrogens against cardiovascular disease, but one mechanism at least could be through effects on nitric oxide synthase activity. We have not, in this study, established whether the midcycle increase in nitric oxide production is derived from constitutive or inducible nitric oxide synthase activity; nor do we know at present which particular hormone is affecting nitric oxide production. None the less, one hypothesis is that the midcycle rise in oestrogen activity modulates nitric oxide synthase and nitric oxide production. In women the midcycle surge of nitric oxide production could influence adaptation of both the arterial and venous vascular beds to increases in flow, protecting against hypertension. Together with the action of nitric oxide inhibiting platelet aggregation, this could contribute to protecting against cardiovascular disease in women.

In conclusion, we measured the peak expiratory concentration of nitric oxide in healthy volunteers and found concentrations considerably higher than those previously reported. We also showed changes in nitric oxide production with the menstrual cycle. Further studies are required to define the precise relation of endogenous nitric oxide production to hormone concentrations and to investigate the possible implications of such data.

We thank the Hyman Marks Fund for support.

1 Palmer RMJ, Ashton DS, Moncada S. Vascular endothelial cells synthesise nitric oxide from L-arginine. Natur 1988;333:664-6.

2 Palmer RMJ, Ferrige AG, Moncada S. Nitric oxide release accounts for the biological activity of endothelium derived relaxing factor. Nature 1987;327:524-6.

3 Moncada S, Palmer RMJ, Higgs EA. Nitric oxide: physiology, pathophysiology, and pharmacology. Pharmacol Rev ogy, pathophysi

4 Gustafsson LE, Leone AM, Persson MG, Wiklund NP, Moncada $S$. Endogenous nitric oxide is present in the Moncada $S$. Endogenous nitric oxide is present in the exhaled air of rabbits, guinea pigs and

5 Van Buren GA, Yang DS, Clark KE. Estrogen-induced uterine vasodilation is antagonised by L-nitroarginine methyl ester, an inhibitor of nitric oxide synthesis. $A m f$ Obstet Gynecol 1992;3:828-33.

6 Bland JM, Altman DG. Statistical methods for assessing agreement between two methods of clinical measurements. Lancet 1986;1:307-10.

7 Bush TL, Barret-Connor E, Cowan LD, Criqui MH, Wallace RB, Suchindran CM, et al. Cardiovascular mortality and noncontraceptive use of estrogen in women results from the lipid research clinics program follow-up study. Circulation 1987;75:1102-9.

8 Rosano GMC, Sarrel PM, Poole-Wilson PA, Collins P. Beneficial effect of oestrogen on exercise-induced myocardial ischaemia in women with coronary artery myocardial ischaemia in women

9 Jiang C, Sarrel PM, Lindsay DC, Polle-Wilson PA Collins P. Endothelium-independent relaxation of rabbi coronary artery by 17 -ostradiol in vitro. $\mathrm{Br} \mathcal{F}$ Pharmacol 1991;104:1033-7.

10 Gisclard V, Miller VM, Vanhoutte PM. Effect of 17 betaoestradiol on endothelial responses in rabbit. $f$ Pharmacol Exp Ther 1988;244:19-22.

11 Williams JK, Adams MR, Herrington DM, Clakson TB Short-term administration of estrogen and vascula responses of atherosclerotic coronary arteries. $7 \mathrm{Am} \mathrm{Coll}$ Cardiol 1992;20:452-7.

12 Williams JK, Adams MR, Klopfenstein HS. Estrogen modulates responses of atherosclerotic coronary arteries. Circ Res 1990;81:1680-7.

13 Colditz GA, Willet WC, Stampfer MJ, Rosner B, Speizer $\mathrm{FE}$, Hennekens $\mathrm{CH}$. Menopause and the risk of coronary heart disease in women. $N$ Engl $f$ Med nary heart diseas

14 Stampfer MJ, Colditz GA, Willet WC, Manson JE, Rosner B, Speizer FE, et al. Postmenopausal estrogen therapy B, Speizer FE, et al. Postmenopausal estrogen therapy 325:756-62. 